\title{
Rhabdomyolysis, Acute Renal Failure and Hepatopathy Induced by Lovastatin Monotherapy
}

\author{
Po-Hsien Chu, MD, Wei-Jan Chen, MD, \\ Cheng-Wen CHIANG, MD, \\ and Ying-Shiung LEE, MD
}

\section{SUMmaRY}

Lovastatin is a popular drug for the treatment of hypercholesterolemia. Few serious complications are associated with its use although rhabdomyolysis with renal failure has been reported when lovastatin is combined with cyclosporine or other drugs following transplantation. We report the case of a patient who developed hepatopathy and rhabdomyolysis accompanied by acute renal failure after 4 weeks of lovastatin monotherapy. The pathogenesis and treatment of these complications are also discussed. (Jpn Heart J 1997; 38: $541-545)$

Key words: Lovastatin, Rhabdomyolysis, Acute renal failure

T OVASTATIN, a 3-hydroxy-3-methylglutaryl coenzyme A (HMG-CoA) reductase inhibitor, is widely used for the treatment of hypercholesterolemia. Lovastatin-induced rhabdomyolysis has been reported associated with the concomitant use of other drugs. ${ }^{1-16)}$ We report a rare case of rhabdomyolysis with acute renal failure and hepatopathy induced by lovastatin monotherapy.

\section{Case Report}

A 55-year-old female was admitted to the hospital because of dizziness, general malaise, tarry stool and poor appetite of 3 days duration. No dyspnea, chest pain, palpitations, syncope, fever, myalgia, seizures, oliguria or abdominal fullness were reported. She had undergone successful percutaneous transvenous coronary angioplasty just 20 days earlier for typical angina pectoris with a critically eccentric $95 \%$ stenosis of the proximal left anterior descending coronary artery. No renal or liver abnormalities were detected at that time. For 26 days

From the First Cardiovascular Division, Department of Internal Medicine, Chang Gung Memorial Hospital, Taipei, Taiwan.

Address for correspondence: Po-Hsien Chu, MD, the First Cardiovascular Division, the Department of Internal Medicine, Chang Gung Memorial Hospital. 199, Tung Hwa North Road, Taipei, Taiwan 105.

Received for publication October 31, 1996.

Accepted January 27, 1997. 
Table. Laboratory Findings

\begin{tabular}{ll}
\hline \multicolumn{1}{c}{ Component } & \\
\hline Serum urea nitrogen $(\mathrm{mg} / \mathrm{d} l)$ & 77 \\
Creatinine $(\mathrm{mg} / \mathrm{d} l)$ & 1.9 \\
ASAT/ALAT $(\mathrm{IU} / l)$ & $1394 / 619$ \\
ALP $(\mathrm{IU} / \mathrm{l})$ & 53 \\
$\gamma$-GTP $(\mathrm{IU} / l)$ & 9 \\
Bilirubin $(\mathrm{mg} / \mathrm{d} l)$ & 0.4 \\
LDH (IU $/ l)$ & 1080 \\
Creatine kinase $(\mathrm{IU} / l)$ & 8996 \\
MM isoenzyme & $100 \%$ \\
Cholesterol $(\mathrm{mg} / \mathrm{d} l)$ & 183 \\
Triglyceride $(\mathrm{mg} / \mathrm{d} l)$ & 120 \\
Sodium $(\mathrm{meg} / l)$ & 143 \\
Potassium $(\mathrm{meq} / l)$ & 5.0 \\
Calcium $(\mathrm{mg} / l)$ & 8.8 \\
Phosphorus $(\mathrm{mg} / l)$ & 5.8 \\
Uric acid $(\mathrm{mg} / \mathrm{d} l)$ & 9.7 \\
Prothrombin time & $10.1 / 12.1$ \\
Hemoglobin $(\mathrm{g} / \mathrm{d} l)$ & 9.9 \\
Platelet count $\left(10^{+} / \mu l\right)$ & 21.7 \\
White blood cell count $\left(10^{3} / \mu l\right)$ & 11.6 \\
Myoglobinuria & positive reaction \\
\hline
\end{tabular}

ASAT $=$ aspartate aminotransferase; ALAT $=$ alanine aminotransferase; ALP $=$ alkaline phosphatases; $\gamma$ GTP $=\gamma$-glutamyl-transpetidase; $\mathrm{LDH}=$ lactate dehydrogenase.

before admission, she had taken lovastatin $20 \mathrm{mg}$ twice daily for hyperlipidemia of IIb phenotype. Her detailed lipid profile was as fellows: total cholesterol 255 $\mathrm{mg} / \mathrm{d} l$, low-density lipoprotein (LDL) $170 \mathrm{mg} / \mathrm{d} l$, very low-density lipoprotein (VLDL) $55 \mathrm{mg} / \mathrm{d} l$, high-density lipoprotein (HDL) $30 \mathrm{mg} / \mathrm{d} l$, and triglyceride $220 \mathrm{mg} / \mathrm{d} l$. In addition to lovastatin, her treatment regimen consisted of isosorbid dinitrate $30 \mathrm{mg}$, propranolol $30 \mathrm{mg}$, tapal (aspirin) $100 \mathrm{mg}$, and diltiazem $90 \mathrm{mg}$ daily. She has been in a stable condition without any recurrent symptoms of angina or shock.

Physical examination revealed a blood pressure of 136/76 $\mathrm{mm} \mathrm{Hg}$. There was no jaundice, pitting edema or skeletal muscle tenderness; however, she complained of back soreness. The major laboratory data are summarized in the Table. Autoimmune antibody tests (anti-nuclear, anti-mitochondrial, and antismooth-muscle antibodies) were all negative. Bacterial and hepatitis viral serology analyses were negative. Thyroid hormone levels were within normal limits.

Lovastatin treatment was stopped 2 days after admission. Hemorrhagic gastritis and duodenal erosions required blood transfusions along with $\mathrm{H}-2$ blockers and antacids four days after admission. Aggravated non-oligouric acute renal failure with a creatinine clearance of $3.6 \mathrm{ml} / \mathrm{min}$ was treated with hemodialysis on one occasion 9 days later. Histochemical analysis and electron 
microscopy of a muscle biopsy specimen showed increased angulated atrophic fibers and positive NADH stain, but was negative for ATPase, Gommoritrichrome, SDH, and PAS stains. The diagnosis was felt to be acute rhabdomyolysis with secondary acute renal failure and hepatopathy induced by lovastatin treatment.

Her symptoms improved progressively following hemodialysis and her renal function returned to nearly normal 3 weeks later. Following discharge she received regular out-patient department follow-up and had no recurrence of symptoms over an 18 month period.

\section{Discussion}

Lovastatin is a well-tolerated and effective drug for the control of hypercholesterolemia. Adverse reactions in multicenter trials have been minor. ${ }^{17-}$ 20) The side effects are generally minor and include rash, constipation and abdominal pain. However, a few serious complications, including hepatopathy, myopathy and rhabdomyolysis have been reported. ${ }^{1-21)}$ Marked persistent elevations in liver function tests were reported in 1.9 percent of patients treated with lovastatin. ${ }^{17}$ ) The abnormalities are often observed within 6 weeks of starting therapy and normalize after lovastatin is discontinued. Our patient had used lovastatin for 4 weeks prior to her admission with rhabdomyolysis.

Myopathy of skeletal muscle including asymptomatic elevations in creatinine kinase level, myalgias, weakness and severe rhabdomyolysis occurred in approximately $0.5 \%$ of patients during a controlled clinical trial. ${ }^{18)}$ The duration of lovastatin therapy prior to the onset myopathy varies from a few weeks, as in our patient, to more than one year. The most severe adverse reaction is rhabdomyolysis accompanied by acute renal failure. This has been observed in heart or kidney transplant patients receiving concomitant drugs, such as cyclosporine, ${ }^{1-3)}$ which increase muscular toxicity. Toxic interactions including rhabdomyolysis have also been reported when lovastatin is used in conjunction with nicotinic acid, ${ }^{4)}$ gemfibrozil, ${ }^{5-11)}$ cholestyramine, ${ }^{13)}$ erythromycin, ${ }^{12)}$ and ketoconazole. Lovastatin monotherapy resulting in rhabdomyolysis, acute renal failure and hepatopathy is very rare. ${ }^{21)}$

The mechanism of lovastatin-induced rhabdomyolysis is not well understood. Lovastatin is metabolized by hepatic microsomes, and notable interactions may occur when it is used in conjunction with other drugs that are metabolized in a similar manner. This hypothesis may explain the effect of lovastatin-induced rhabdomyolysis when lovastatin is given in conjunction with other drugs metabolized in the liver by the cytochondrome P-450 system. ${ }^{16)}$ By inhibiting the hepatic microsomal P-450 system, co-administered drugs such as erythromycin may in- 
crease serum levels of lovastatin. Both of these drugs are also highly bound to serum protein. These additional drugs may further raise serum lovastatin levels by displacing the drug from protein-binding sites. HMG-CoA reductase inhibitors may inhibit mitochondrial production of ATP, leading to inadequate synthesis of $\mathrm{CoQ}$ and heme $\mathrm{A}$ in the inner mitochondrial membrane, with subsequent derangement of cellular energy production and cell death. ${ }^{23)}$ Electron-microscopic studies of skeletal muscle have revealed extensive mitochondrial damage compatible with this pathophysiology.

Based on these findings, measurement of serum creatine kinase (CK) level is recommended for all patient receiving lovastatin treatment when muscle weakness or myalgia develops. It is also recommended that lovastatin therapy be temporarily withdrawn should any condition develop that is known to predispose patients to the development of rhabdomyolysis, including severe infection, hypotension, major surgery, trauma, severe metabolic, endocrine, or electrolyte disorders, and uncontrolled seizures. ${ }^{10)}$

While lovastatin therapy is effective and generally safe for patients with hypercholesterolemia, it is still necessary to be aware of the early symptoms of rhabdomyolysis and to respond appropriately to these symptoms, even when the patient is not receiving a treatment combination which is recognized for its potential to induce complications.

\section{REFERENCES}

1. Corpier CL, Jones PH, Suki WN, et al. Rhabdomyolysis and renal injury with lovastatin use: report of two cases in cardiac transplant recipients. JAMA 1988; 260: 239-41.

2. Norman DJ, Dlingworth DR, Munson J, Hosenpud J. Myolysis and acute renal failure in a hearttransplant recipient receiving lovastatin (letter). N Engl J Med 1988; 318: 46-7.

3. East C, Alivizatos PA, Grundy SM, Jones PH, Farmer JA. Rhabdomyolysis in patients receiving lovastatin after cardiac transplantation (letter). N Engl J Med 1988; 318: 47-8.

4. Reaven P, Witztum JL. Lovastatin, nicotinic acid and rhabdomyolysis (letter). Ann Intern Med 1988; 109: 597-8.

5. Ayanina JZ, Fuchx CX, Stones RM. Lovastatin and rhabdomyolysis (letter). Ann Intern Med 1988; 109: $682 \cdots 3$.

6. Goldman JA, Fishman AB, Lee JE, Johnson RJ. The role of cholesterol-lowing agents in drug-induced rhabdomyolysis and polymyositis (letter). Arthritis Rheum 1989; 32: 358-9.

7. Kogan AD, and Orenstein S. Lovastatin-induced acute rhabdomyolysis. Postgrad Med J 1990; 66: 294-6.

8. Manoukian AA, Bhagava NV, Hayashi T, Nestor TA, Rios C, Scottolini AG. Rhabdomyolysis secondary to lovastatin therapy. Clin Chem 1990; 36: 2145-7.

9. Marais GE, Larson KK. Rhabdomyolysis and acute renal failure induced by combination lovastatin and gemfibrozil therapy. Ann Intern Med 1990; 112: 228-30.

10. Pierce LR, Wysowski DK, Gross TP. Myopathy and rhabdomyolysis associated with lovastatingemfibrozil combination therapy. JAMA 1990; 267: 71-5.

11. Sylvain-Moore H, Worden JPJ. Lovastatin-associated rhabdomyolysis. Heart Lung 1991; 20: 464-6.

12. Spach DH, Bauwens JE, Clark CD, Burke WG. Rhabdomyolysis associated with lovastatin and erythromycin use. West J Med 1991; 154: 213-5. 
13. Chrysanthopoulos C, Kounis N. Rhabdomyolysis due to combined treatment with lovastatin and cholestyramine. BMJ 1992; 304: 1225.

14. Zatarain GF, Navarro V, Garcia $\mathrm{H}$, Villatoro J, Calvo C. Rhabdomyolysis and acute renal failure associated with lovastatin (letter). Nephron 1994; 66: 483-4.

15. Alejandro DS, Petersen J. Myoglobinuric acute renal failure in a cardiac transplant patient taking lovastatin and cyclosporine. J Am Soc Neph 1994; 5: 153-60.

16. Marinella MA. More on lovastatin. West J Med 1995; 162: 176-7.

17. Lovastatin Study Group II. Therapeutic response to lovastatin (mevenolin) in nonfamilial hypercholesterolemia. JAMA 1986; 256: 2829 34.

18. Tobert JA. Efficacy and long-term adverse effect pattern of lovastatin. Am J Cardiol 1988; 62: 28J$34 \mathrm{~J}$.

19. The Lovastatin Study Group III. A multicenter comparison of lovastatin and cholestyramine therapy for severe primary hypercholesterolemia: a multicenter study. JAMA 1988; 260: 359-66.

20. Bradford RH, Shear CL, Chremos AN, et al. Expanded clinical evaluation of lovastatin (EXCEL) study results. 1. Efficacy in modifying plasma lipoproteins and adverse event profile in 8245 patients with moderate hypercholesterolemia. Arch Intern Med 1991; 151: 43-9.

21. Wallace CS, Mueller BA. Lovastatin-induced rhabdomyolysis in the absence of concomitant drugs. Ann Pharmacol 1992; 26: 190-2. 